\title{
Introduction: genetic biocontrol of invasive fish species
}

\author{
Anne R. Kapuscinski • Leah M. Sharpe
}

Received: 10 March 2014/ Accepted: 14 March 2014/Published online: 3 April 2014

(C) The Author(s) 2014. This article is published with open access at Springerlink.com

This special issue of Biological Invasions presents articles resulting from the International Symposium on Genetic Biocontrol of Invasive Fish that was convened June 21-24, 2010 in Minneapolis, Minnesota, USA (http://www.seagrant.umn.edu/ais/biocontrol). The symposium explored prospects and risks of genetic biocontrol-a new technological approach for controlling invasive finfish species that have established populations in natural ecosystems. The frustration by some fisheries managers regarding lack of well-targeted and effective tools to control invasive fish stimulated the organizing of this symposium (Kapuscinski and Patronski 2005).

The motivations for and development of any technology are not divorced from influences of society and nature. Instead, technology is part of a coevolutionary process of change involving interactions and feedbacks among values, systems of knowledge, institutions, technology and the environment (Norgaard 1994:27). This context-dependence is rarely treated explicitly, credibly and genuinely in technology development and assessment. Such a crucial

\footnotetext{
A. R. Kapuscinski $(\bowtie)$

Environmental Studies Program 6182 Steele Hall, Dartmouth College, Hanover, NH 03755, USA

e-mail: Anne.R.Kapuscinski@Dartmouth.Edu

L. M. Sharpe

Conservation Biology Graduate Program, University of

Minnesota, Saint Paul, MN 55108, USA
}

omission has contributed to undesired outcomes after deployment of new technologies: unintended consequences, social resistance, and, in some cases, failure to achieve stated goals (Norgaard 1994; NRC 1996; Gibbons 1999; Kapuscinski et al. 2003). The fact that genetic biocontrol technology is at an early stage of research and development offers a rare opportunity to take a wiser approach. We therefore designed this symposium to address genetic biocontrol technology per se and its crucial contextual factors.

The symposium brought together scientific and policy researchers, fisheries managers, representatives of fishing groups, businesses and environmental groups, and government regulators to start building a comprehensive understanding of issues regarding development and use this technology. Specific objectives were to:

- review the status of genetic biocontrol technologies for aquatic invasive species (with a focus on finfish) and develop an agenda for future research and development;

- review best available methods for environmental risk assessment and develop a roadmap for risk assessment of genetic biocontrol of aquatic invasive species;

- discuss stakeholder involvement in development and assessment of this technology;

- consider economic costs of the impacts of aquatic species invasions and of genetic biocontrol of such invasive species; and 
- examine the regulatory context for governing genetic biocontrol of invasive fishes and recommend governance improvements.

Genetic biocontrol refers to the intentional environmental release of genetically manipulated organisms that are designed to disrupt the survival or reproduction of a targeted invasive species. It involves manipulations of chromosomes of a target species in order to skew sex ratios of the target species, recombinant DNA techniques to insert a deleterious gene construct into the target species' genome in order to disrupt the organism's life cycle, or a combination of both techniques. Genetic biocontrol strategies have the potential to better target a specific invasive species of concern and possibly achieve shorter time periods of maintenance than current control methods such as physical removal or rotenone poisoning. Intentionally releasing a genetically manipulated organism into the wild, however, is a controversial idea and raises questions about various risks. Turning genetic biocontrol methods into practical tools will require thorough assessment of these risks and identifying ways to mitigate them.

Current control techniques available for aquatic invasive species are time and labor intensive, expensive, and often lethal for non-target species. Genetic biocontrol technology offers frustrated natural resource managers a new opportunity for a different control strategy. Thresher et al. (2013) review the current state of this technology, which ranges from the well-developed option of releasing sterile males produced by chromosomal manipulations to recombinant and Trojan $\mathrm{Y}$ chromosome options that are potentially more effective than sterile male release but presently require more research and development. They also explore the potential to enhance the effectiveness of control by using these genetic technologies within an integrated pest management approach. Research efforts have not yet progressed to the point of testing the efficacy of this technology with live organisms in well-secured but ecologically relevant confined mesocosms. Researchers are thus using quantitative models to explore questions about efficacy. Modeling informed by the international symposium suggests that both chromosome and gene manipulations show the potential to eradicate populations of invasive species, albeit requiring time frames on the order of decades to achieve extinction (Teem et al. 2013); and that combining these techniques may speed up the process (Teem and Gutierrez 2013).

The promise of genetic biocontrol technologies comes with questions about effectiveness, development costs, opportunity costs, and ecological risks. Sharpe (2013) reports that stakeholders in focus groups raised all these categories of questions, with their concerns ranging from whether the technology would function as intended in the wild to how to prevent spread of biocontrol organisms beyond the target area. Participants attending the symposium raised similar concerns during the symposium break out groups. The fact that genetic biocontrol technologies requires deliberate release and spread into nature of genetically manipulated organisms makes it paramount to precede any deployment of genetic biocontrol with state-ofthe-art environmental risk assessment as outlined by Dana et al. (2013) and using quantitative methods within an evidence-based framework as presented by Hayes et al. (2013). Homans and Smith (2011) present a framework for estimating costs and benefits of genetic biocontrol and investigate the critical issue of when investing in genetic biocontrol is economically justified. These four articles give technology developers a roadmap for responsible development and assessment of this technology.

Policymakers and regulators will also face new governance challenges with the development of genetic biocontrol technologies at national and international levels. Showalter Otts (2012) examines the current US regulatory framework and identifies significant weaknesses and outright gaps for regulating environmental applications of genetic biocontrol. Internationally, governance of genetic biocontrol deployments will be challenging, for example, regarding the responsibilities one nation will have to another if it allows deployment of genetic biocontrol within its jurisdiction but cannot fully preclude spread to transboundary waters. Gilna et al. (2013) examine international agreements and treaties, as well as highlight the differences among national regulatory regimes, to identify key weaknesses in international oversight and recommend broad options for resolving these limitations. They identify, for example, that the Cartagena Protocol on Biosafety, the most relevant international agreement, clearly applies to a genetic biocontrol organism produced by recombinant-DNA manipulations but likely not to a genetic biocontrol organism produced solely by chromosomal 
manipulations. Garforth and Miranda (2012) focus on the Cartagena Protocol on Biosafety to explain the rules that Parties (signatory countries) must follow for transboundary movements of "living modified organisms" that might adversely affect biodiversity; and end by noting that the Parties have not yet developed specific guidance for applying the Protocol to modified fish.

This collection of articles provides principles, knowledge and methodologies for taking an analyticdeliberative approach to the development and governance of genetic biocontrol. Any future deployment of genetic biocontrol technology into natural ecosystems to manage invasive fish - and indeed to manage any invasive taxon-would be an action that affects the public trust due to its application in natural ecosystems. The value of iteration between analysis by scientists and other experts and then deliberation with potentially affected and interested parties is that it improves both the scientific credibility of decisions and the capacity to earn social acceptance of decisions affecting the public trust (NRC 1996; Kapuscinski et al. 2007; NRC 2008; Nelson et al. 2009). As a first step towards a well-designed analytic-deliberative process, these papers build upon presentations, discussions and relationships begun at the symposium. We hope that these articles stimulate additional research to better understand the effectiveness and risks of genetic biocontrol and wise evolution of policy to improve governance of this technology.

A broad range of support was critical to the symposium and this collection of articles. Our sincere appreciation goes to Dartmouth College, the Gila River Basin Native Fishes Conservation Program, the Great Lakes Protection Fund, the Introduced Species and Genotypes-IGERT Program at the University of Minnesota, Minnesota Sea Grant, the Mississippi River Basin Panel on Aquatic Nuisance Species, the Murray-Darling Basin Authority in Australia, the U.S. Department of Interior Bureau of Reclamation, the US Fish and Wildlife Service, the US Fish and Wildlife Service CAP Transfer Program, and the US Department of Agriculture Biotechnology Risk Assessment Grants Program. This wide range of support clearly demonstrates the broad interest in the idea of genetic biocontrol, as well as the interdisciplinary approach needed for future development and decision-making regarding this technology.
Open Access This article is distributed under the terms of the Creative Commons Attribution License which permits any use, distribution, and reproduction in any medium, provided the original author(s) and the source are credited.

\section{References}

Dana GV, Cooper AM, Pennington KM, Sharpe LS (2013) Methodologies and special considerations for environmental risk analysis of genetically modified aquatic biocontrol organisms. Biol Invasions. doi:10.1007/s10530012-0391-x

Garforth K, Miranda M (2012) The Cartagena Protocol on Biosafety and living modified fish. Biol Invasions. doi:10. 1007/s10530-012-0388-5

Gibbons M (1999) Science's new social contract with society. Nature 402:C81-C84

Gilna B, Kuzma J, Sholwater Otts S (2013) Governance of genetic biocontrol technologies for invasive fish. Biol Invasions. doi:10.1007/s10530-012-0367-X

Hayes KR, Leung B, Thresher R, Dambacher J, Hosack GR (2013) Meeting the challenge of quantitative risk assessment for genetic control techniques: a framework and some methods applied to the common Carp (Cyprinus carpio) in Australia. Biol Invasions. doi:10.1007/s10530-012-0392-9

Homans FR, Smith DJ (2011) Evaluating management options for aquatic invasive species: concepts and methods. Biol Invasions. doi:10.1007/s10530-011-0134-4

Kapuscinski AR, Patronski TJ (2005) Genetic methods for biological control of non-native fish in the Gila river basin. Contract report to the US Fish and Wildlife Service. University of Minnesota, Institute for Social Economic and Ecological Sustainability. MN Sea Grant Publication F 20. Available at www.seagrant.umn.edu/publications/F20

Kapuscinski AR, Goodman RM, Hann SD, Jacobs LR, Pullins EE, Johnson CS, Krall JD, Kinsey RL, La Viña AGM, Mellon MG, Ruttan VW (2003) Making safety first a reality for biotechnology products. Nat Biotechnol 21(6):599-601

Kapuscinski AR, Hayes KR, Li S, Dana G (eds) (2007) Environmental risk assessment of genetically modified organisms: methodologies for transgenic fish, vol 3. CAB International, Wallingford

National Research Council (NRC) (1996) Understanding risk: informing decisions in a democratic society. National Academy Press, Washington DC

National Research Council (NRC) (2008) Public participation in environmental assessment and decision making. National Academies Press, Washington, DC

Nelson KC, Andow DA, Banker MJ (2009) Problem formulation and option assessment (PFOA) linking governance and environmental risk assessment for technologies: a methodology for problem analysis of nanotechnologies and genetically engineered organisms. J Law Med Ethics 37:732-748

Norgaard R (1994) Development betrayed: the end of progress and a coevolutionary revisioning of the future. Routledge, London

Sharpe L (2013) Public perspectives on genetic biocontrol technologies for controlling invasive fish. Biol Invasions. doi:10.1007/s10530-013-0545-5 
Showalter Otts S (2012) US regulatory framework for genetic biocontrol of invasive fish. Biol Invasions doi: 10.1007/ s10530-012-0327-5

Teem JL, Gutierrez JB (2013) Combining the Trojan Y chromosome and daughterless carp eradication strategies. Biol Invasions. doi:10.1007/s10530-013-0476-1

Teem JL, Gutierrez JB, Parshad RD (2013) A comparison of the Trojan Y chromosome and daughterless carp eradication strategies. Biol Invasions. doi:10.1007/s10530-013-0475-2
Thresher RE, Hayes K, Bax NJ, Teem J, Benfey TJ, Gould F (2013) Genetic control of invasive fish: technological options and its role in integrated pest management. Biol Invasions. doi:10.1007/s10530-013-0477-0 